\title{
Prevalence of Urinary and Intestinal Schistosomiasis Among Rice Framers in Asutsuare, Ghana
}

\author{
Michael Fokuo Ofori ${ }^{1, *}$, Bernard Opoku Peprah ${ }^{2}$, Selorme Adukpo ${ }^{1,3}$, Emmanuel Kakra Dickson ${ }^{1}$, \\ Isaac Anim-Baidoo ${ }^{2}$, Richard Henry Asmah ${ }^{2}$ \\ ${ }^{1}$ Immunology Department, Noguchi Memorial Institute for Medical Research, College of Health Sciences, University of Ghana, Legon, Ghana \\ ${ }^{2}$ Department of Microbiology, School of Basic and Allied Health Sciences, College of Health Sciences, University of Ghana, Legon, Ghana \\ ${ }^{3}$ Department of Pharmaceutics and Microbiology, School of Pharmacy, College of Health Sciences, University of Ghana, Legon, Ghana
}

Email address:

Mofori@noguchi.ug.edu.gh (M. F. Ofori), benopokupeprah@yahoo.com (B. P. Opoku), adukpo@noguchi.ug.edu.gh (S. Adukpo), Edickson@noguchi.ug.edu.gh (E. K. Dickson), IAnim-baidoo@chs.edu.gh (I. Anim-Baidoo), rhasmah@chs.edu.gh (R. H. Asmah) ${ }^{*}$ Corresponding author

\section{To cite this article:}

Michael Fokuo Ofori, Bernard Opoku Peprah, Selorme Adukpo, Emmanuel Kakra. Dickson, Isaac Anim-Baidoo, Richard Henry Asmah. Prevalence of Urinary and Intestinal Schistosomiasis Among Rice Framers in Asutsuare, Ghana. International Journal of Microbiology and Biotechnology. Vol. 5, No. 2, 2020, pp. 69-73. doi: 10.11648/j.ijmb.20200502.14

Received: March 25, 2020; Accepted: April, 2020; Published: May 28, 2020

\begin{abstract}
Schistosomiasis (urinary and intestinal) is a chronic, water-borne parasitic disease caused by blood flukes of the genus Schistosoma. The disease poses health problems in Ghana and is known to be associated with recreational and agricultural activities that involving frequent contact with freshwater. This study, therefore, determined the prevalence of urinary and intestinal Schistosomiasis among rice farmers in Asutsuare, a rural farming community in the Greater Accra Region of Ghana. A total of 150 study participants comprising of 88 farmhands (people hired to work on rice farm) and 62 rice farm owners of both sexes with ages between 15-68 years were involved. Urine and stool samples were collected from study participants. Urine samples were tested for haematuria, proteinuria and while stool samples were examined under the microscope for schistosome ova. A structured questionnaire was used to gather demographic data and other significant information from the study participants. The prevalence of urinary and intestinal schistosomiasis each among the study group was $19.3 \%$ and $2 \%$ respectively. The overall prevalence (prevalence of $S$. haematobium and S. mansoni put together) was (21.33\%). The disease was mostly seen among farmhands with the prevalence of the two disease conditions being $21.6 \%$ and $3.4 \%$ for urinary and intestinal respectively. The prevalence of urinary schistosomiasis among the farm owners was $16.1 \%$, but no intestinal schistosomiasis was detected. Both urinary and intestinal schistosomiasis are prevalent in the study area. The farm helps on rice farms are at a higher risk of contracting the disease than the farm/land owners.
\end{abstract}

Keywords: Urinary, Intestinal, Schistosomiasis, Rice Farmers, Farmhands, Ghana

\section{Introduction}

Human schistosomiasis is a complex of acute and chronic waterborne parasitic infections that is caused by a neglected blood vessel dwelling trematode of genus Schistosoma. Two forms of the disease exist; intestinal Schistosomiasis caused by Schistosoma. mansoni, S. mekongi, S. intercalatum, $S$. japonicum, $S$. guineensis and urinary schisitosomiasis which is caused by $S$. haematobium occur [1]. The disease widely distributed in tropical and subtropical regions, especially in the developing countries. About 700 million people, particularly those living in riverine regions where the water flow rate is low are at greatest risk of contracting the disease. The greatest burden, however, is borne by African countries, south of the Sahara desert [1]. Schistosomiasis is endemic to Ghana [2] possibly because Ghana is endowed with several rivers, including River Volta and its tributaries. This geographical terrain, coupled with water-associated industrial, agricultural and domestic activities have made the Schistosoma parasites and their water snail vectors to thrive in Ghana. Infection occurs when the larval form of the parasite (cercariae) emerges from freshwater snail and 
penetrates the skin of the definitive human host during contact with infested freshwater.

Farming is the major occupation of the people in and around Asutsuare with rice being the main crop grown. The rice is grown twice a year with water for irrigation provided by the Kpong irrigation project which was established by the Government of Ghana. Activities on the farms expose farmers to the schistosomes which may be present in the irrigation water since schistosomiasis is associated with fresh water contact-activities [3] like recreational (swimming) or specific agricultural activities (eg. rice farming) [4,5]. On the farms of Asutsuare, farmers consist of landowners and farmhands who carry out most of the farm activities and may be at a greater risk of contracting schistosomiasis. This study, therefore, sort to assess the occurrence of schistosomiasis among these two groups of people in Asutsuare, Ghana,

\section{Materials and Methods}

\subsection{Study Area}

The study was conducted at Asutsuare in the Shai-Osudoku district of the Greater Accra region, Ghana. Asutsuare is located about $60 \mathrm{~km}$ East of Tema and 8km East of Akuse on the South-west bank of River Volta.

\subsection{Sampling and Laboratory Examination of Samples}

Urine and stool samples were taken from each participant between April and June 2014 upon completion of a questionnaire. From each of them, a clean catch terminal urine sample (10ml-15ml) was collected into a clean, leak-proof, screw capped, sterile and dry wide mouth urine container. The containers were labelled appropriately with the study participants' identification code. The sample collection was done between the hours of 10:00 am and 2:00 pm. The labelled stool containers were shared among participants to be sent home and brought the next morning with stool sample produced that morning. Samples were put in an ice chest with ice packs around before being transported to the laboratory. The urine and stool samples were transported to the Osudoku Health Centre laboratory for analyses. The urine and stool samples were examined within 3-8 hours after collection following physical examination and urine biochemistry test. The nature (colour and appearance) of urine and stool (colour and consistency) samples were documented. Each urine sample was also examined for any visible evidence of turbidity and haematuria and recorded. Haematuria and proteinuria were determined and recorded using urinalysis strips. Each commercially prepared reagent strip (Kroma 10E Test) was dipped into each urine sample and the colours developed were matched with standard colours by the side of the container of the reagent strips.

Centrifugation and formyl-ether sedimentation techniques [6] were employed to process the urine and stool samples respectively.

Schistosome ova were counted and classified according to the method described that considers number of eggs present in $10 \mathrm{ml}$ of urine in grading the severity of infection. Thus1-9 eggs/10ml means is described as light infections, 10-49 eggs $/ 10 \mathrm{ml}$ indicates moderate infections and $>50 \mathrm{eggs} / 10 \mathrm{ml}$ is indicative of heavy infections,

Intensities of intestinal schistosomiasis are as follows; 1-99 egg per gram of stool means light, 100-399 eggs per gram of stool translate into moderate infections and $\geq 400$ eggs per gram of stool means heavy infections [7].

\subsection{Ethical Approval}

The School of Biomedical and Allied Health Sciences, University of Ghana, ethics committee approved this study (Ethics approval no.: SAHS-ET/10333718/AA/23A/2013-2014). Participation was voluntary and written informed consent was obtained from each participant after permission was sought from the chief and leaders of the community.

\section{Results}

A total of 150 participants were involved in this study. The study focused on rice farmers in Asutsuare. Of the 150 participants $91(60.7 \%)$ were males of which $38(41.8 \%)$ owned farm (owners) and $53(58.2 \%)$ were employed to work on rice farms as farmhands. The remaining 59 (39.3\%) of the participants were females of which 24 (40.7\%) owned farm and $35(59.3 \%)$ were farmhands. The respective mean ages and corresponding standard deviation with respect to gender are shown (Table 1).

Regarding their level of education, it was found out that 38 $(25.3 \%)$ of the total number who participated in the study had no formal education, $43(28.7 \%)$ had primary education, 36 (24.0\%) had Junior secondary education, (9.3\%) had Middle.

Table 1. Demographic Characteristics of Study Participants.

\begin{tabular}{llll}
\hline Parameters & Total $(\mathbf{n = 1 5 0})$ & Male $(\mathbf{n}=\mathbf{9 1})$ & Females $(\mathbf{n}=\mathbf{5 9})$ \\
\hline $\begin{array}{l}\text { Age (mean } \pm \text { SD years) } \\
\text { Type of Farmers n (\%) }\end{array}$ & $35.73 \pm 1.055$ & $35.20 \pm 1.453$ & $36.54 \pm 1.482$ \\
Owners & $62(41.3 \%)$ & $38(41.8 \%)$ & $24(40.7 \%)$ \\
Farm hand & $88(58.7 \%)$ & $53(58.2 \%)$ & $35(59.3 \%)$ \\
\hline
\end{tabular}

The data on age of study participants are presented as mean values followed by standard deviation while that of farmers presented as counts with percentage in parenthesis. In all comparisons, a $\mathrm{p}<0.05$ was considered significant.

School education, $12(8.0 \%)$ had Senior secondary education, 14 and $7(4.7 \%)$ had tertiary education.

The questionnaire also revealed that all participants [150
$(100 \%)]$ had contact with the irrigation water. It was found that all participants have access to tap water but sometimes resort to the river and canal for water related activities like 
swimming. Regarding haematuria, the urine chemistry showed that $121(80.7 \%)$ tested negative for blood in urine whereas $29(19.3 \%)$ tested positive for it (Table 2). Also, 121
(80.7\%) tested negative for protein whereas 29 (19.3\%) tested positive for protein (Table 2). Stool macroscopic examination results showed that $3(2 \%)$ had blood stained stool (Table 2).

Table 2. Frequency of proteinuria, haematuria and S. haematobium infection and frequency of blood in stool and S. mansoni infections.

\begin{tabular}{|c|c|c|c|c|c|c|c|c|c|}
\hline & \multirow{2}{*}{ Participants $(n=150)$} & \multicolumn{2}{|c|}{ Gender } & \multicolumn{2}{|c|}{ Category of farmers } & \multicolumn{4}{|c|}{ Age group } \\
\hline & & Male & Female & Owner & Farm hand & $\leq 18$ & 19-38 & $39-58$ & $59-78$ \\
\hline \multicolumn{10}{|l|}{ Haematuria } \\
\hline+ & 10 & 8 & 3 & 3 & 8 & 0 & 7 & 3 & 0 \\
\hline++ & 19 & 13 & 5 & 7 & 11 & 2 & 12 & 5 & 0 \\
\hline $\begin{array}{l}\text { Total no. infected } \\
\text { Proteinuria }\end{array}$ & $29(19.3 \%)$ & 21 & 8 & 10 & 19 & 2 & 19 & 8 & \\
\hline+ & 11 & 9 & 3 & 2 & 9 & 0 & 8 & 3 & 0 \\
\hline++ & 5 & 4 & 1 & 0 & 4 & 2 & 3 & 0 & 0 \\
\hline+++ & 13 & 8 & 4 & 8 & 6 & 0 & 8 & 5 & 0 \\
\hline $\begin{array}{l}\text { Total no. infected } \\
\text { Blood in stool }\end{array}$ & $29(19.3 \%)$ & 21 & 8 & 10 & 19 & 2 & 19 & 8 & \\
\hline Present & 3 & 3 & 0 & 0 & 3 & 1 & 2 & 0 & 0 \\
\hline Total no. infected & $3(2.0 \%)$ & & & & & & & & \\
\hline
\end{tabular}

The data are presented as counts with percentages in parenthesis.

The microscopy revealed that all urine and stool samples that were positive contained only $S$. haematobium and $S$. mansoni ova respectively and without dual infections. In all,
$29(19.3 \%)$ of the total number of participants were infected with Schistosoma haematobium and $3(2 \%)$ were infected with Schistosoma mansoni (Tables 3 and 4 respectively).

Table 3. Age and gender distribution of S. haematobium infection.

\begin{tabular}{|c|c|c|c|c|c|}
\hline & \multirow{2}{*}{$\begin{array}{l}\text { Total examined } \\
n=150\end{array}$} & \multirow{2}{*}{$\begin{array}{l}\text { No. } \text { infected } \\
\mathrm{n}=29(19.3 \%)\end{array}$} & \multicolumn{3}{|c|}{ Intensity of infections } \\
\hline & & & Light $n=16$ & Moderate $n=10$ & Heavy $n=3$ \\
\hline \multicolumn{6}{|l|}{ Age range } \\
\hline$\leq 18$ & 10 & $2(20.0 \%)$ & 0 & 2 & 0 \\
\hline $19-38$ & 78 & $19(24.3 \%)$ & 12 & 4 & 3 \\
\hline $39-58$ & 54 & $8(14.8 \%)$ & 4 & 4 & 0 \\
\hline $59-78$ & 8 & 0 & 0 & 0 & 0 \\
\hline \multicolumn{6}{|l|}{ Gender } \\
\hline Female & 59 & $8(13.6 \%)$ & 4 & 3 & 1 \\
\hline \multicolumn{6}{|c|}{ Category of farmers } \\
\hline Owners & 62 & $10(16.1 \%)$ & 5 & 4 & 1 \\
\hline Farmhands & 88 & $19(21.6 \%)$ & 11 & 6 & 2 \\
\hline
\end{tabular}

Table 4. Age and gender distribution of S. mansoni infection.

\begin{tabular}{|c|c|c|c|c|c|}
\hline & \multirow{2}{*}{$\begin{array}{l}\text { Total examined } \\
\mathrm{n}=150\end{array}$} & \multirow{2}{*}{$\begin{array}{l}\text { No. infected } \\
n=3(2.0 \%)\end{array}$} & \multicolumn{3}{|c|}{ Intensity of infections } \\
\hline & & & Light $n=3$ & Moderate $n=0$ & Heavy $n=0$ \\
\hline \multicolumn{6}{|l|}{ Age range } \\
\hline$\leq 18$ & 10 & $1(10.0 \%)$ & 1 & 0 & 0 \\
\hline $19-38$ & 78 & $2(2.6 \%)$ & 2 & 0 & 0 \\
\hline $39-58$ & 54 & 0 & 0 & 0 & 0 \\
\hline $59-78$ & 8 & 0 & 0 & 0 & 0 \\
\hline \multicolumn{6}{|l|}{ Gender } \\
\hline Female & 59 & 0 & 0 & 0 & 0 \\
\hline \multicolumn{6}{|c|}{ Category of farmers } \\
\hline Owners & 62 & 0 & 0 & 0 & 0 \\
\hline Farmhands & 88 & 3 & 3 & 0 & 0 \\
\hline
\end{tabular}

\section{Discussion}

Schistosomiasis is of much public health concern, especially, in developing countries. It imposes extensive economic and health implications to residents living in endemic areas. The prevalence of schistosomiasis (urinary and intestinal) among rice farmers, both farm owners and farmhands, in Asutsuare, Greater Accra Region of Ghana was evaluated. The causative agents detected were $S$. mansoni and S. haematobium, a finding which concur well with earlier report indicating that $S$. haematobium and $S$. mansoni are responsible for the disease in Ghana [8, 9]. Schistosoma. haematobium was observed in a higher frequency in the study area suggesting that at least in that area the major schistosoma parasite circulating is $S$. haematobium. This possibly puts the 
people in the area at risk of developing structural abnormalities of the urinary system, including, obstructive uropathy, bladder cancer that have been linked to urinary schistomiasis [10-14]. The lower prevalence of S. mansoni infection compared to that of $S$. haematobium could have been due to the intensity of infection and sensitivity of the formyl-ether sedimentation techniques [6] used in comparison to the centrifugation followed by microscopy employed in the evaluation of $S$. haematobium infection. The above notwithstanding, indiscriminate open defaecation, especially, near and in the freshwater bodies might have been very low in the area to impact negatively on $S$. mansoni transmission intensity to result in its low prevalence. The possibility of the $S$. mansoni infected individual migrating to the area in recent time could also not be ruled out.

The level of infection was found to be higher among males than females; a situation similar to reports from other parts of Africa [15-17]. This might have resulted from the extent to which these two genders interact with water. A great proportion of males than females engage in agricultural/farming activities such as tilling of land, transplanting of rice seedlings and application of fertilizer which are performed when the field is wet. Behavioural, recreational (swimming) and cultural differences in gender roles (washing of clothes and utensils, farming activities) have been associated with schistosomiasis among males and females [16]. Information gathered from the records of the Osudoku health centre (unpublished) revealed that more females than males frequently visit the facility to be treated for various ailments, including schistosomiasis. This could have also resulted in the disparity as some of the females who probably contracted the disease in the past might have been treated at the time of sampling.

Often, farmhands engage in more farming activities such as transplanting of seedlings and application of fertilizers which are done while the farms are still wet compared to farm owners. These practices expose the workers to contaminated water and possible infection throughout the period that they work on the farms. This could have accounted for the higher level of infection in the farmhands than in the farm owners.

The presence of $S$. haematobium eggs in urine was significantly associated with proteinuria and haematuria as all the 29 study participants who had $S$. haematobium infection were also positive for proteinuria and haematuria. This finding is as expected since the migration of the spiny S. haematobium eggs is associated with lesions, and ulcerations in the lumens of the ureter and bladder, which subsequently causes haematuria. The current result is also in agreement with earlier reports [18, 19] and thus indicative of an active infection rather than past infection.

\section{Conclusion}

The prevalence of urinary schistosomiasis (19.3\%) and intestinal schistosomiasis (2\%) was recorded. It is essential, however, to note that the prevalence level detected in the current study could be an underestimation of the actual infection level, as only one sample/slide each of stool and urine per participant was used for the estimation. Even though the sampling procedure is a drawback of the study, it is worthwhile to note that these two Schistosoma spp are prevalent in the study area and present us with the problems associated with them. Therefore, there is the need to tackle these parasites to free the community from these infections.

\section{Acknowledgements}

Our sincere gratitude goes to the participants and the staff of the Immunology Department for their enormous support throughout the study.

\section{References}

[1] Chitsulo L, Engels D, Montresor A, Savioli L: The global status of schistosomiasis and its control. Acta Trop 2000, 77: 41-51.

[2] Pulinx EM, Kolopp M, Drouin P: [Technical reliability and clinical acceptance of the Nordisk insulin injection pen]. Journ Annu Diabetol Hotel Dieu 1989, 321-328.

[3] Ndassa A, Mimpfoundi R, Gake B, Paul Martin MV, Poste B: Risk factors for human schistosomiasis in the Upper Benue valley, in northern Cameroon. Ann Trop Med Parasitol 2007, 101: 469-477.

[4] Matthys B, Tschannen AB, Tian-Bi NT, Comoe H, Diabate S, Traore $\mathrm{M}$ et al.: Risk factors for Schistosoma mansoni and hookworm in urban farming communities in western Cote d'Ivoire. Trop Med Int Health 2007, 12: 709-723.

[5] Raso G, Matthys B, N'Goran EK, Tanner M, Vounatsou P, Utzinger J: Spatial risk prediction and mapping of Schistosoma mansoni infections among schoolchildren living in western Cote d'Ivoire. Parasitology 2005, 131: 97-108.

[6] WHO. The Schistosomiasis Control: Second Report of The WHO Expert Committee. 1993. World Health Organization Technical Report Series.

[7] Tarafder MR, Balolong E Jr, Carabin H, Belisle P, Tallo V, Joseph L et al.: A cross-sectional study of the prevalence of intensity of infection with Schistosoma japonicum in 50 irrigated and rain-fed villages in Samar Province, the Philippines. BMC Public Health 2006, 6: 61.

[8] Ayeh-Kumi PF, Obeng-Nkrumah N, Baidoo D, Teye J, Asmah RH: High levels of urinary schistosomiasis among children in Bunuso, a rural community in Ghana: an urgent call for increased surveillance and control programs. J Parasit Dis 2015, 39: 613-623.

[9] Lodh N, Mikita K, Bosompem KM, Anyan WK, Quartey JK, Otchere $\mathrm{J}$ et al.: Point of care diagnosis of multiple schistosome parasites: Species-specific DNA detection in urine by loop-mediated isothermal amplification (LAMP). Acta Trop 2017, 173: 125-129.

[10] Antwi S, Aboah KE, Sarpong CK: The unacknowledged impact of urinary schistosomiasis in children: 5 cases from Kumasi, Ghana. Ghana Med J 2014, 48: 228-233.

[11] Berry A, Iriart X, Fillaux J, Magnaval JF: [Urinary schistosomiasis and cancer]. Bull Soc Pathol Exot 2017, 110: 68-75. 
[12] Botelho MC, Alves H, Richter J: Estrogen catechols detection as biomarkers in schistosomiasis induced cancer and infertility. Lett Drug Des Discov 2017, 14: 135-138.

[13] Dematei A, Fernandes R, Soares R, Alves H, Richter J, Botelho $\mathrm{MC}$ : Angiogenesis in Schistosoma haematobium-associated urinary bladder cancer. APMIS 2017, 125: 1056-1062.

[14] Shiff C, Veltri R, Naples J, Quartey J, Otchere J, Anyan W et al.: Ultrasound verification of bladder damage is associated with known biomarkers of bladder cancer in adults chronically infected with Schistosoma haematobium in Ghana. Trans $R$ Soc Trop Med Hyg 2006, 100: 847-854.

[15] Agnew-Blais J, Carnevale J, Gropper A, Shilika E, Bail R, Ngoma M: Schistosomiasis haematobium prevalence and risk factors in a school-age population of peri-urban Lusaka, Zambia. J Trop Pediatr 2010, 56: 247-253.

[16] Curtale F, Hassanein YA, Barduagni P, Yousef MM, Wakeel $\mathrm{AE}$, Hallaj $\mathrm{Z}$ et al.: Human fascioliasis infection: gender differences within school-age children from endemic areas of the Nile Delta, Egypt. Trans R Soc Trop Med Hyg 2007, 101: 155-160.

[17] Kapito-Tembo AP, Mwapasa V, Meshnick SR, Samanyika Y, Banda D, Bowie $\mathrm{C}$ et al.: Prevalence distribution and risk factors for Schistosoma hematobium infection among school children in Blantyre, Malawi. PLoS Negl Trop Dis 2009, 3: e361.

[18] Mafe MA, von ST, Utzinger J, N'Goran EK: Control of urinary schistosomiasis: an investigation into the effective use of questionnaires to identify high-risk communities and individuals in Niger State, Nigeria. Trop Med Int Health 2000, 5: 53-63.

[19] Suthiphosuwan S, Lin A, Gao AF, Munoz DG, Spears J, Bharatha A: Delayed presentation of cerebral schistosomiasis presenting as a tumor-like brain lesion. Neuroradiol $J$ 2017, 1971400917703991. 